\title{
The Benefits of Whole-Genome Sequencing Now and in the Future
}

\author{
Alina Khromykh ${ }^{\mathrm{a}}$ Benjamin D. Solomon ${ }^{\mathrm{a}-\mathrm{c}}$ \\ a Division of Medical Genomics, Inova Translational Medicine Institute, and b Inova Children's Hospital, Inova Health \\ System, Falls Church, Va., and 'Department of Pediatrics, Virginia Commonwealth University (VCU) School of \\ Medicine, Richmond, Va., USA
}

\section{Key Words}

Genome - Genomic information · Personalized medicine .

Precision medicine $\cdot$ Strong signals $\cdot$ Whole-genome sequencing

Growing attention has been paid to the concept of 'precision' or 'personalized' medicine, buoyed recently in the US by President Obama's commitment to large-scale genomics [Collins and Varmus, 2015]. While there has been considerable enthusiasm in many spheres, the movement has not been without vocal opponents.

In a recent Los Angeles Times op-ed piece entitled 'Why whole-genome testing hurts more than it helps' (http://www.latimes.com/opinion/op-ed/la-oe-welchproblems-predictive-medicine-20150428-story.html), Drs. H. Gilbert Welch, Professor of Medicine at Dartmouth Medical School, and Wylie Burke, Professor of Bioethics and Humanities at the University of Washington, argue that investing in genomics in the way President Obama describes is a misguided approach, largely because the 'research is bound to produce more noise than signal'. In other words, there are too many variables and too many different combinations of genomic and clinical data to detect meaningful patterns.

\section{KARGER 125}

(c) 2015 S. Karger AG, Basel

$1661-8769 / 15 / 0063-0108 \$ 39.50 / 0$

E-Mail karger@karger.com

www.karger.com/msy
Additionally, the authors raise concerns about using weak signals for medical guidance. By 'weak signals', the authors mean genetic markers that, in their words, 'are associated with changes in risk of a few percentage points - for example, increasing your chance of developing Disease X from $4 \%$ to 6\%'. They point out that there may be value in detecting strong signals (they give the example of mutations that substantially increase the risk of colon cancer) but argue that detecting these can be done without whole-genome sequencing. The authors also write that these strong signals are already largely known and thus do not require further investigation.

We would argue - and we readily admit bias, as we are actively involved in large-scale genomic studies [Solomon, 2014b] - that the authors of the op-ed piece might entertain several considerations before dismissing personalized or precision medicine so promptly.

First, our knowledge of all the strong signals in the human genome is in fact increasing steadily. For example, in the past 2 years, over 12 new Mendelian disease genes have been published per month [Solomon, 2014b]. This rate of discovery has been largely driven by the same new sequencing technologies that enable Obama's emphasis on genomic medicine [Boycott et al., 2013; Hayden, 2014, Solomon, 2015]. To borrow Welch and Burke's analogy, while the fruit do not hang as low as previously, the tools

Benjamin D. Solomon

Department of Pediatrics, VCU School of Medicine

3300 Gallows Road, 2nd Floor, Claude Moore Building

Falls Church, VA 22042 (USA)

E-Mail benjamin.solomon@inova.org 
for harvesting these fruit are almost unimaginably better than before. As a consequence of the continuing new discoveries, although a person's genome may not reveal obvious strong signals on first analysis, part of the value of genomics is that data can be stored and analyzed as knowledge accrues, or as more patients with similar phenotypes are identified; in the realm of Mendelian disorders, there are multiple endeavors to encourage this type of collaboration [Gottlieb et al., 2015]. This would clearly not be possible with a targeted assay.

Second, while many inherited genetic conditions are individually rare, they are common in aggregate; approximately 3-5\% of infants are recognized as having genetic disorders and/or birth defects that may involve genetic factors [McIntosh et al., 1954; Centers for Disease and Prevention, 2008]. To the counterargument that whole-genome sequencing should be used only when a disorder of possible genetic cause is evident, many genetic conditions are not recognizable at birth, such that $\sim 8 \%$ of people are found to be affected by early adulthood [Baird et al., 1988]. And a significant proportion of the population may have other medically relevant variants that do not present a priori with clinical signs (e.g. 1-2\% of the population should avoid codeine due to the potential for toxicity, while for another 5-10\%, codeine should be avoided due to lack of efficacy) [Crews et al., 2014; Lam et al., 2014].

To further support the clinical utility of achieving a molecular diagnosis, for almost exactly half of all the known Mendelian disease genes, there is an indicated intervention, whether involving surveillance, preventive measures, or medical or surgical therapy, upon identification of a mutation [Solomon et al., 2013; Solomon, 2015].
In other words, it would be beneficial to detect thousands of individual conditions at an early stage rather than waiting until they become clinically apparent.

Third, and most fundamentally, Welch and Burke argue that investing in precision medicine is misguided because they believe that most of the time whole-genome sequencing is an unhelpful test. Again, this unhelpfulness rests on the premise of weak (and often unclear) signals, and the authors, as well as others, are very correct stating that we should not oversell the ability to fully interpret the information in the human genome [Solomon, 2014a]. But we would posit that the push for whole-genome sequencing, despite some of the advantages mentioned above, should focus on collecting large-scale clinical, genomic, and other relevant biological data in order to allow the development of new tools and approaches to handle these data sets and surmount the challenging (in the best sense of the word) statistical problems described in the op-ed piece [Flores et al., 2013]. Along the way, an important responsibility will be to ensure that opportunists do not seize on financial possibilities to (mis)guide vulnerable individuals in the way Welch and Burke aptly describe.

In summary, the availability of genomic information can be used to extract strong signals immediately and be stored for future detection of newly discovered strong signals. Furthermore, genetic information can also be a key to understanding the causes of health and disease. This is not an easy or quick task and will require significant investment and personal, institutional, and governmental buy-in. However, with time and hard work, whole-genome testing can certainly help.

\section{References}

Baird PA, Anderson TW, Newcombe HB, Lowry RB: Genetic disorders in children and young adults: a population study. Am J Hum Genet 42:677-693 (1988).

Boycott KM, Vanstone MR, Bulman DE, MacKenzie AE: Rare-disease genetics in the era of next-generation sequencing: discovery to translation. Nat Rev Genet 14:681-691 (2013).

-Centers for Disease Control and Prevention (CDC): Update on overall prevalence of major birth defects - Atlanta, Georgia, 19782005. MMWR Morb Mortal Wkly Rep 57:1-5 (2008).

Collins FS, Varmus H: A new initiative on precision medicine. N Engl J Med 372:793-795 (2015).

Crews KR, Gaedigk A, Dunnenberger HM, Leeder JS, Klein TE, et al: Clinical Pharmacogenet- ics Implementation Consortium guidelines for cytochrome P450 2D6 genotype and codeine therapy: 2014 update. Clin Pharmacol Ther 95:376-382 (2014).

-Flores M, Glusman G, Brogaard K, Price ND, Hood L: P4 medicine: how systems medicine will transform the healthcare sector and society. Per Med 10:565-576 (2013).

Gottlieb MM, Arenillas DJ, Maithripala S, Maurer ZD, Tarailo Graovac M, et al: GeneYenta: a phenotype-based rare disease case matching tool based on online dating algorithms for the acceleration of exome interpretation. Hum Mutat 36:432-438 (2015).

Hayden EC: Technology: The \$1,000 genome. Nature 507:294-295 (2014).

Lam J, Woodall KL, Solbeck P, Ross CJ, Carleton $\mathrm{BC}$, et al: Codeine-related deaths: the role of pharmacogenetics and drug interactions. Forensic Sci Int 239:50-56 (2014).

McIntosh R, Merritt KK, Richards MR, Samuels MH, Bellows MT: The incidence of congenital malformations: a study of 5,964 pregnancies. Pediatrics 14:505-522 (1954).

Solomon BD: Incidentalomas in genomics and radiology. N Engl J Med 370:988-990 (2014a).

Solomon BD: Obstacles and opportunities for the future of genomic medicine. Mol Genet $\mathrm{Ge}$ nomic Med 2:205-209 (2014b).

Solomon BD: Genomic sequencing and the impact of molecular diagnosis on patient care. Mol Syndromol 6:4-6 (2015).

Solomon BD, Nguyen AD, Bear KA, Wolfsberg TG: Clinical genomic database. Proc Natl Acad Sci USA 110:9851-9855 (2013). 